\title{
Neuroticism Predicts Reactions to Cues of Social Inclusion
}

\author{
JAAP J. A. DENISSEN ${ }^{1 *}$ and LARS PENKE ${ }^{2}$ \\ ${ }^{1}$ Humboldt University Berlin, Germany \\ ${ }^{2}$ University of Edinburgh, UK
}

\begin{abstract}
In the current paper, we hypothesized that people who are high in neuroticism (N) share a motivational predisposition to react vigilantly to threatening cues, most of which tend to be social in humans. In three studies, support for this prediction was found: based on cross-sectional and diary data, it was found that the self-esteem (SE) of individuals high in $N$ decreases more in response to perceptions of relationship conflict and low relationship quality than that of emotionally stable ones. In a study of people's reactions to imagined threats, neurotic individuals showed a heightened sensitivity to both nonsocial and social cues, though reactions to social cues were somewhat more pronounced. Results are consistent with principles from evolutionary and process-oriented personality psychology. Copyright (C) 2008 John Wiley \& Sons, Ltd.
\end{abstract}

Key words: neuroticism; social inclusion; close relationships; self-esteem; sociometer theory

\section{INTRODUCTION}

Neuroticism $(\mathrm{N})$ is a personality dimension that is described by adjectives such as tense (vs. relaxed), nervous (vs. at ease) and moody (vs. steady) and inversely labelled emotional stability. The correlates of this trait are profound including low subjective well-being, perceptions of low physical health, maladaptive reactions to illness, higher levels of psychopathology, less mature levels of identity achievement and a lower quality of social and romantic relationships (Ozer \& Benet-Martínez, 2006). Against this background, it is all the more worrying that mean levels of this trait seem to be on the rise since the 1950s (Twenge, 2000). Thus, it is no wonder that, of all the big five factors, $\mathrm{N}$ is most often mentioned in the PsycINFO database. However, in spite of this large body of research, it is still not clear what the fundamental nature of $\mathrm{N}$ is. In this paper, we present findings from a cross-sectional and a diary study that link $\mathrm{N}$ to individual differences in the predisposition to react to perceive cues of social exclusion

*Correspondence to: Jaap J. A. Denissen, Humboldt University Berlin, Germany. E-mail: jjadenissen@ gmail.com 
as threatening. In addition, we assessed people's imagined reaction to social and nonsocial threats and correlated both types of reactivity with individual differences in $\mathrm{N}$.

\section{Existing conceptualizations of neuroticism}

Neuroticism derives from the word 'neurosis', which was introduced by the Scottish physician William Cullen in 1769 to refer to 'disorders of sense and motion' caused by a 'general affection of the nervous system'. This is consistent with the view that individual differences in $\mathrm{N}$ represent differences in mental noise (operationalized as reaction time standard deviations; Robinson \& Tamir, 2005). Another conceptualization regards $\mathrm{N}$ as a general negative emotionality (Tellegen, 1985). According to this notion, high-N individuals have a higher likelihood than emotionally stable individuals to experience feelings of anxiety and depression (Church, 1994). This conceptualization is consistent with the view that traits can be thought of as density distributions (i.e. likelihoods) of states (Fleeson, 2001).

However, it can be questioned whether high-N people indiscriminately display unstable responses, negative emotions and related behavioural tendencies, regardless of what is actually happening to them. Indeed, such rigid conceptualizations of personality traits that lack a reference to the kinds of situations in which it is relevant have been questioned from an evolutionary genetic perspective (Penke, Denissen, \& Miller, 2007a,b), and from a process-oriented personality perspective as well, as eloquently formulated by Revelle (1995):

Traits are not behaviour. They are summary statements describing likelihood of and rates of change in behaviour in response to particular situational cues. In addition to their relationship to the probability and latency of a response, stable predispositions may be conceptualized in terms of differential sensitivities to situations and differential response rates (p. 315, italics added).

In Eysenck's (1944, 1990) PEN model, $\mathrm{N}$ has been related to activation thresholds in the sympathetic nervous system or brain regions that govern fight-or-flight responses when confronted with danger. This perspective has received ample support from research on individual differences in the responsiveness of the avoidance (vs. approach) system (Carver, Sutton, \& Scheier, 2000; Elliot \& Thrash, 2002; Zuckerman, Joireman, Kraft, \& Kuhlman, 1999). The N-as-sensitivity-to-threats hypothesis meets the requirement that it specifies a context (threats) that activates the propensity of high-N individuals to react in a certain way (with vigilance).

\section{THE ECOLOGICAL SALIENCE OF SOCIAL INCLUSION}

Research has demonstrated a central role of $\mathrm{N}$ in the reactivity to a variety of threatening cues such as emotional (especially aversive) stimuli (Gross, Sutton, \& Ketelaar, 1998; Norris, Larsen, \& Cacioppo, 2007), negative feedback (Larsen \& Ketelaar, 1989) and the occurrence of daily problems (Suls, Green, \& Hillis, 1998). This evidence is consistent with a conceptualization of $\mathrm{N}$ as tapping into people's predisposition to react vigilantly to threatening cues. In the present paper, we argue that once humans had acquired ecological dominance (i.e. a state where conspecifics have become a more important evolutionary selection pressure than other species or the physical environment, see Alexander, 1990; 
Flinn \& Alexander, 2007), solving social (vs. nonsocial) problems became an increasingly salient adaptive challenge, which may have led to a 'socialization' of an originally generalized system to monitor and react to threats. If this logic is correct, the threat-monitoring system that is $\mathrm{N}$ should be often, but not exclusively, focused on social threats (Matthews, 2004). Consistent with this, Zautra, Affleck, Tennen, Reich, and Davis (2005) found that $\mathrm{N}$ is associated with a heightened reactivity to interpersonal stressors.

The hypothesis that high-N individual are more sensitive to cues of social rejection explicitly links this trait to the sociometer theory (SMT) of self-esteem (SE; Leary \& Baumeister, 2000; Leary, Tambor, Terdal, \& Downs, 1995). According to Leary and Baumeister (2000), SE serves as a gauge or 'sociometer' to monitor people's level of belongingness, or social inclusion. Specifically, at low levels of social inclusion, 'the sociometer evokes emotional distress as an alarm signal and motivates behaviours to gain, maintain and restore relational appreciation' ( $\mathrm{p}$. 12). Therefore, on days when they feel socially included, people should feel better about themselves than on days when they feel isolated from others. These fluctuations have been shown to occur around relatively stable baseline levels of SE, which differ between people (i.e. trait SE). According to Leary and Baumeister (2000), this baseline feeling is partly determined by past experiences of being rejected or included. In this paper, we propose that the 'socialized' version of the threat surveillance system that underlies individual differences in $\mathrm{N}$ reflects individual differences in the sensitivity of people's sociometers.

Although the wide variety of negative outcomes that are associated with $\mathrm{N}$ suggests that this traits is exclusively maladaptive, SMT points to possible advantages of having a highly sensitive system to monitor social threats. Specifically, if people monitor their existing relationships, they can adjust their behaviour when the quality of these social bonds is deteriorating instead of waiting until they are broken, when efforts at repair may be much more difficult. Research by Heatherton and Vohs (2000) demonstrates that this can be an effective strategy, as people with low SE have been found to be perceived as more likeable by interaction partners after receiving an ego threat than people with high SE. Because threats to the ego are usually associated with decreases in state SE (though note that people with inflated high SE may counteract this association; Bushman \& Baumeister, 1998), the process hypothesized by SMT is very similar to our hypothesis that $\mathrm{N}$ is related to individual differences in the motivational predisposition to feel threatened by cues of social exclusion.

In addition, a situationally contingent conceptualization may explain the maintenance of genetic differences in $\mathrm{N}$ over evolutionary time, which is much more difficult if this trait is only seen as maladaptive ( $c f$. Watson \& Casillas, 2003). According to the current perspective, the adaptive benefits of $\mathrm{N}$ depend in part on the necessity of social bonds, which varies with certain features of the environment. For example the evolutionary pay-offs of cooperative social relationships (and stable romantic relationships in particular) vary with the importance of biparental childcare, which is contingent on the harshness of the physical and sociocultural environment (Gangestad \& Simpson, 2000; Harpending \& Cochran, 2002). The adaptive value of a (stably) sensitive monitor of threats to relationship stability is therefore conditional to the environmental context.

\section{THE CURRENT STUDIES}

The current investigation tested the hypothesis that $\mathrm{N}$ is associated with individual differences in people's sensitivity to cues of social exclusion. This hypothesis borrows 
from modern theories about the nature of SE (Leary \& Baumeister, 2000) and scattered evidence is consistent with it (Murray, Griffin, Rose, \& Bellavia, 2003; Srivastava \& Beer, 2005). Using both cross-sectional and diary data, the focus in Studies 1 and 2 was on two indicators of social inclusion: relationship quality and conflict. These dimensions have been demonstrated to be relatively independent from each other (Neyer \& Lehnart, 2007) and represent push and pull factors influencing people's decision to establish and maintain social relationships. Finally, Study 3 compared participants' reactions to imagined social and nonsocial threats in terms of their association with $\mathrm{N}$.

\section{STUDY 1: CROSS-SECTIONAL CONTINGENCIES OF SELF-ESTEEM}

As stated above, SMT (Leary \& Baumeister, 2000), predicts that feelings of high SE are contingent on gaining other people's approval. Study 1 tests the prediction that the SE of high-N individuals is more contingent on perceptions of social inclusion. For this purpose, data from a cross-sectional survey on social networks and general SE were analysed. We expected that a statistical interaction would be found between $\mathrm{N}$ and indicators of social inclusion in predicting global SE. Specifically, it his hypothesized that the global SE of high- $\mathrm{N}$ individuals is more dependent on their perceived level of social inclusion than that of emotionally stable individuals.

\section{Method of Study 1}

\section{Sample}

The sample used in Study 1 was originally collected for an unrelated project on cognitive differences and social relationships. Because this project required sample stratification according to GPA, the university examinations office of a large metropolitan German university was asked to provide the addresses of the university graduates whose final grade belonged to the top $14 \%$ or middle $14 \%$ of the GPA distribution of their study major. ${ }^{1}$ Data collection was carried out in three waves between March 2003 and June 2003, with a total of 543 questionnaires being sent out. In the end, 261 individuals contributed at least some data (response rate 48\%). However, two participants reported an unrealistic age, and 43 participants did not complete the scales that were used in the current study, reducing the final sample to 216 individuals. Of these, 120 were female, 88 male and 8 individuals did not indicate their gender. The average age was 27.26 years $(\mathrm{SD}=2.65)$.

\section{Procedure}

Participants filled out the measures used in the present study at home. To answer participants' questions regarding the study's procedure, a special email address and telephone hotline was created, but this option was only rarely used. The order of the presentation of the scales was fixed, starting with the social network instrument, followed by assessments of $\mathrm{N}$ and SE. For the participants' convenience, an online

\footnotetext{
${ }^{1}$ We checked for any differences between the different GPA achievement groups in terms of main and interactive effects but these were never statistically significant. Accordingly, group membership was collapsed in subsequent analyses.
} 
version of the questionnaire was created, an opportunity that was used by 41 individuals $(19 \%)$.

\section{Measures}

Participants' social networks were assessed with a measure taken from Asendorpf and Wilpers (1998) and Neyer (1997). In a first step, this instrument requires participants to list a maximum of 35 important persons with whom they interact at least once per month $(M=22.71, \mathrm{SD}=8.41$, range 6-35). Relationships were sampled from a wide range of family and non-family categories, with an average number of 1.00 mothers, 0.94 fathers, 3.71 other family members, 0.68 partners and 10.20 friends. Additionally, data on age, gender, relationship duration (between $1=$ less than 1 year and $4=$ more than 5 years) and contact frequency (between $1=$ once per month or less and $5=$ daily) were collected. In the current sample, the average age of contact persons was $34.54(\mathrm{SD}=16.97)$, with $53 \%$ being female. The mean relationship duration and contact frequency were $3.21(\mathrm{SD}=0.41)$ and $2.45(\mathrm{SD}=0.47)$, respectively.

Perceived social inclusion was assessed separately for each listed social relationship with six items tapping into the following dimensions (in order of appearance): felt closeness in the relationship $(1=$ very distant, $5=$ very close $)$, frequency of conflict ( $1=$ never, 5 = almost always), opportunity for meaningful communication (about themes that are subjectively important: $1=$ not at all, $5=$ very good), availability of emotional support $(1=$ never, $5=$ for almost every problem $)$, felt understanding $(1=$ very much misunderstood, $5=$ very much understood $)$ and felt acceptance $(1=$ not at all accepted, $5=$ completely accepted).

Perceived social inclusion ratings were aggregated across all social relationships in participants' social networks, resulting in relatively normal item distributions. After this, we subjected all ratings to a principal component factor analysis. Parallel analysis indicated that only the eigenvalues of the first two factors exceeded the $95 \%$ confidence interval of the eigenvalues that could be expected by change. Together, these two factors explained $74 \%$ of the variance. Rotating these factors with OBLIMIN resulted in a correlation of -.17 between the two principal components. We therefore decided to use VARIMAX rotation to obtain orthogonal factors. The first factor, explaining $55 \%$ of the variance, was characterized by high primary loadings $(>0.70)$ of the felt closeness, meaningful communication, emotional support, felt understanding and acceptance ratings. Accordingly, these items were aggregated into a scale of relationship quality $(\alpha=.87)$. The second factor, explaining $19 \%$ of the variance, was almost solely dominated by ratings of conflict frequency: The primary factor loading of the corresponding item was 0.91 , with secondary loadings ranging only between -0.35 and 0.28 . Accordingly, this variable was retained as a single-item indictor of relationship conflict.

$\mathrm{N}$ was measured by the corresponding 12-item scale of the NEO-FFI (Costa \& McCrae, 1992; German adaptation by Borkenau \& Ostendorf, 1993), using a 5-point Likert scale $(\alpha=.84)$. Responses of the participants were highly similar to a representative sample of 1908 German adults, collected by Körner, Geyer, and Brähler (2002), with an average $z$-value of $-0.18(\mathrm{SD}=1.02)$.

SE was assessed with a short 4-item version of the German Self Description Questionnaire III (SDQ-III; Marsh, 1992), using a 5-point Likert scale $(\alpha=.89, M=4.00$, $\mathrm{SD}=0.76$, range $=1.25-5.00$ ). This scale was developed by Schwanzer (2002) on the basis of item-total correlations of the items of the full scale. 


\section{Analysis strategy}

The hypothesis that $\mathrm{N}$ is associated with greater sensitivity to signs of social inclusion was tested by multiple regression analyses predicting SE using three consecutive blocks of predictors: $\mathrm{N}$, social inclusion and their interaction term.

\section{Results of Study 1}

\section{Main effects}

As can be seen in Table $1, \mathrm{~N}$ was highly related to $\mathrm{SE}$, with a $\beta$ coefficient of -.63 . In the final model including all three predictor blocks, the main effect of perceived relationship quality was significant, $\beta=.18, p<.01$, accounting for $3 \%$ of incremental variance. This finding is consistent with SMT's contention that SE increases when people feel accepted by others. By comparison, relationship conflict was only marginally negatively related to SE, $\beta=-.10, p=.08$, accounting for $1 \%$ of incremental variance. This lower effect size could be due to a lack of reliability due to the single-item nature of this variable.

\section{Interaction effects}

Table 1 also shows the $\beta$ weights, significance levels and effect sizes of the interaction between $\mathrm{N}$ and social relationship characteristics in predicting SE. The interaction between perceived relationship quality and $\mathrm{N}$ was significant, $\beta=.14, p<.01$, accounting for $2 \%$ of incremental variance. In contrast, the interaction effect between relationship conflict and $\mathrm{N}$ was not statistically significant. To flesh out the nature of the interaction effect between relationship quality and $\mathrm{N}$, we used the regression equation to plot the predicted means for three levels of the moderator (1 SD below the mean, the mean and 1 SD above the mean in $\mathrm{N}$ ) in Figure 1 (note that a similar plot was obtained when calculating empirical means). As can be seen, the SE of the high-N group was highly dependent on perceptions of social relationship quality, as indicated by a relatively steep slope. On the other hand, the group of emotionally stable people was relatively independent of perceptions of relationship quality, with individuals with average levels of $\mathrm{N}$ falling in between.

This pattern was replicated when we performed a mean-level split on the data and ran separate regressions for highs and lows. For emotionally stable individuals, the $\beta$ weight indicating the association between $\mathrm{N}$ and relationship quality was non-significant, $\beta=.03$, $p=.73$ (this coefficient did not increase substantially when corrected for the somewhat

Table 1. $\quad \beta$ weights, $t$-values and incremental explained variance from multiple regression analyses predicting self-esteem from neuroticism, indices of perceived social inclusion and their interaction

\begin{tabular}{lcrr}
\hline & $\beta$ & $t$ & $\Delta R^{2}$ \\
\hline Neuroticism & -.63 & $-12.67^{*}$ & .44 \\
Relationship quality & .18 & $3.52^{*}$ & .03 \\
Neuroticism $\times$ relationship quality & .14 & $2.84^{*}$ & .02 \\
Neuroticism & -.63 & $-11.58^{*}$ & .44 \\
Relationship conflict & -.10 & -1.75 & .01 \\
Neuroticism $\times$ relationship conflict & -.04 & -0.71 & .00 \\
\hline
\end{tabular}

Note: $N=216$. Incremental explained variances are based on a model in which neuroticism was entered as a first block, social inclusion was entered as a second block, and the neuroticism $\times$ social inclusion interaction was entered as a third block; $\beta$ coefficients and $t$-values are based on the final 3-block model. ${ }^{*} p<.01$. 


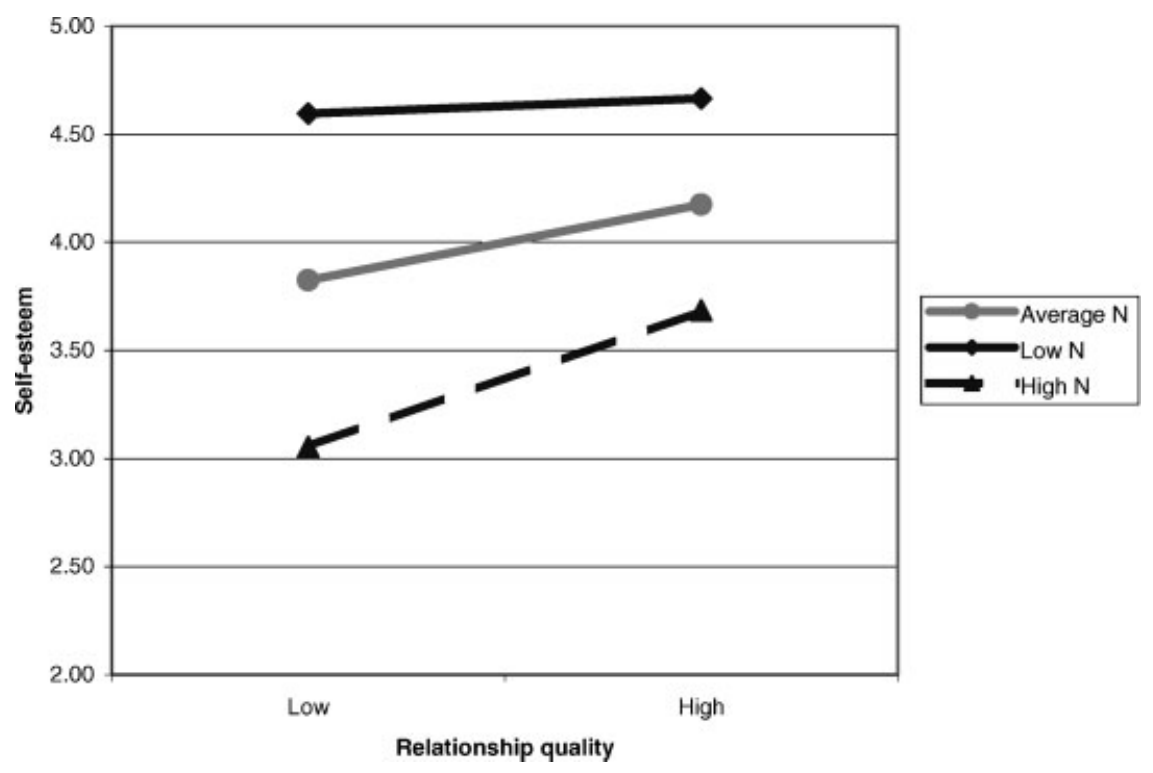

Figure 1. Self-esteem plot of neurotic and emotionally stable participants, depending on their perceived level of relationship quality.

restricted variance of SE in this group). In contrast, for individuals above average in $\mathrm{N}$, a highly significant association was found, $\beta=.45, p<.01$.

\section{Discussion of Study 1}

Study 1 tested the prediction that the SE of high-N individuals is more sensitive to signs of social inclusion than that of emotionally stable ones. As indicators of social inclusion, perceptions of social relationship quality and conflict were used. Support for the validity of this operationalization was found in a main effect of social relationship quality on participants' level of SE, which is consistent with SMT (Leary \& Baumeister, 2000). In contrast, only a marginally significant main effect was found for perceptions of relationship conflict.

In line with our hypothesis, moderator analyses revealed that the association between social relationship quality and SE depended very much on the participants' level of N: individuals high in $\mathrm{N}$ were also highly dependent on the perceived quality of their social relationships, whereas this was much less true for emotionally stable individuals. However, no support was found for the moderating role of $\mathrm{N}$ on the (non-significant) association between relationship conflict and SE.

Although support was found for the moderating role of $\mathrm{N}$ on the association between social inclusion and SE, the bulk of the variance in trait SE was explained by a direct association with N. This replicates Judge, Erez, Bono, and Thoresen's (2002) finding that these constructs are closely related. We think this reflects the fact that constructs are reciprocally related. For example generalized expectations of social rejection (SE) should lead one to feel vulnerable to threats $(\mathrm{N})$. In addition, a high subjective vulnerability to threats likely decreases one's potential value as a social interaction partner, leading to lower levels of SE. In addition to such reciprocal associations, some of the variance shared 
between $\mathrm{N}$ and SE may be due to third factors, such as past experiences of rejection and negative response tendencies (some of these factors may be genetically mediated; e.g. see Raevuori et al., 2007). However, testing the nature of the relationship between N and SE is beyond the scope of this paper.

In spite of the clear results regarding the moderating effect of $\mathrm{N}$ on the association between relationship quality and SE, Study 1 suffers from at least two limitations. First of all, the current assessment of relationship conflict relied only on a single, highly general item, limiting both the reliability and validity of this index. Of course, this is an obvious explanation for the lack of main and interaction effects for this variable. Second, participants rated the global level of relationship quality and conflict with each of their contact persons, which introduces the possibility that associations with SE are due to person-specific response biases (but note that this alternative explanation cannot account for the significant interaction found between $\mathrm{N}$ and social relationship quality). In particular, Study 1 could not offer data reflecting the ups and downs in perceptions of social inclusion across participants' daily lives. For this purpose, Study 2 was carried out.

\section{STUDY 2: DAILY CONTINGENCIES OF SELF-ESTEEM}

In Study 1, it was demonstrated that people who generally perceive a lot of support from their network partners also have a high level of trait SE. This raises the question of whether this relation would also be found between day-to-day fluctuations in the perception of social inclusion and state SE. That is, regardless of how good people generally feel about themselves, it could be that their self-images become clouded on days with negative social interactions, whereas they experience a boost when relationships with important others are very positive. To test this notion, a diary study of daily fluctuations in people's SE and social relations was carried out. Such a design is ideally suited to test the conditional hypothesis that high-N people's SE is more sensitive to signs of social exclusion than that of emotionally stable people.

The idea that $\mathrm{N}$ is involved in people's reactivity to daily events has already been investigated by a number of diary studies on daily stress. Barrett and Pietromonaco (1997) studied people's reactions to stressful social interactions and found no moderating effect of $\mathrm{N}$ on changes in anxiety. However, it should be noted that this study investigated reactions to all social interactions, not just those with emotionally close others, so it is unclear to what degree their operationalization tapped into reactions to threats to existing social relationships. In contrast, Bolger and colleagues (Bolger \& Schilling, 1991; Bolger \& Zuckerman, 1995) found that high-N individuals reacted more intensely to interpersonal conflicts than emotionally stable persons, and Gunthert, Cohen, and Armeli (1999) found that N was associated with more exposure to social, but not nonsocial, stressors, as well as a marginally greater reactivity to social stressors. Finally, using diary data from over 1000 individuals, Mroczek and Almeida (2004) found that individuals high in $\mathrm{N}$ reacted more negatively to a variety of stressors, including interpersonal conflicts. Against this empirical background, it was expected that high-N individuals' daily SE would be more dependent on reports of daily conflicts than that of emotionally stable individuals. Similarly, high-N individuals' SE was predicted to be more dependent on fluctuating perceptions of relationship quality. 


\section{Method of Study 2}

\section{Sample}

Between July 2005 and January 2007, participants took part in a German online diary study, which focused on the determinants of individual daily well-being. Publicity for this study was generated through links on websites dedicated to psychological research as well as postings on online forums. 1692 individuals contributed at least one diary report. Of these, 1433 (85\%) were women and $202(12 \%)$ were men (57 people did not report their gender), with an average age of $27.63(\mathrm{SD}=9.57)$. Slightly less than $50 \%$ were university graduates (including the German Fachhochschule).

\section{Instruments and procedure}

Before taking part in the dairy study, participants completed an extensive pretest questionnaire online. $\mathrm{N}$ was assessed using The Big Five Inventory (BFI; John \& Srivastava, 1999), which had an $\alpha$ of .88. In addition, trait SE was measured with the Rosenberg Self-Esteem Scale (RSES; Rosenberg, 1965), which had an $\alpha$ of .93. After filling out the BFI N-scale, the SE scale and some other measures unrelated to the current study, participants were asked to identify both a friend and a family member with whom they had most contact on average. In addition, the 909 participants (54\% of the sample) who currently were in a committed romantic relationship identified their partners. This was done so that the daily questionnaire could be tailored to refer to specific, personally important relationships.

Upon completing the pretest questionnaire, participants filled out daily questionnaires including measures of social inclusion and SE. The different scales of the daily questionnaires were presented in randomized order to avoid the development of automatic response sets. As an incentive, participants received written feedback (based on intra-individual correlations between daily events and mood) regarding the extent to which a number of factors affected their mood during the course of the study (e.g. amount of sleep, number of social interactions). The hypotheses of the study were not disclosed to the participants and the feedback did not include the social inclusion variables used in the current study. Participants could provide up to 25 questionnaires within 30 days. To minimize recall biases, it was only possible to access the questionnaire between $9 \mathrm{pm}$ and $4 \mathrm{am}$. However, not all participants completed the full 25 questionnaires needed for feedback. On average, participants contributed 13.51 daily reports $(\mathrm{SD}=10.30)$.

If participants had contacted at least one or more of the persons specified at pretest, the corresponding interactions were evaluated with a German adaptation of the Rochester Interaction Record (Nezlek \& Wheeler, 1984), using the following nine items: enjoyment, interest, intimacy, dominance, feeling important, calm, safe, wanted and respected. Separate principal component factor analyses of ratings for friends, family members and partners indicated that all items except dominance loaded highly on a general factor, so these eight were aggregated into a composite scale of relationship quality with good internal consistency $(\alpha \mathrm{s}>.90)$.

Participants checked the occurrence of the following sources of relationship conflict in interactions with contact persons: Financial or material resources, communication difficulties, planning joint activities, long-term life planning, lack of support, conflicting opinions or values, other persons and a rest category. Daily frequencies ranged between 0.02 (long-term life planning with friends) and 0.12 
(communication problems with partner), with an average of 0.05 , suggesting that conflict in relationships is a relatively rare phenomenon. Principle component factor analyses of conflict occurrences indicated a prominent general factor in all cases, so the different conflict sources were aggregated into one relationship-specific index, with $\alpha$ s ranging between .61 (conflict with family members) and .66 (conflicts with partners/friends), which is reasonable given the low conflict frequencies observed in the current study.

To check the independence of relationship conflict and quality as indicators of perceived social inclusion, a hierarchical linear modelling (HLM) analysis predicting daily perceptions of quality from self-reported frequencies of conflict was conducted. Results showed a significantly negative association between both variables, $\beta=-0.40, p<.01$, though its moderate strength indicates that both measures assess somewhat different aspects of social inclusion.

Because people likely base their subjective impressions of social inclusion on interactions with more than one person, relationship-specific ratings were averaged into a global index of relationship quality and a global index of relationship conflict. The reliability of these day-to-day composites was .56 and .46, respectively. In multilevel analysis, this relatively low level of reliability is compensated by the fact that most participants contribute various data points, allowing for a higher level of reliability of individual-level intercepts and slopes (Bryk \& Raudenbush, 1992).

Following Nezlek and Plesko (2003), daily SE was assessed with state formulations of items $3,6,7$, and 10 of the RSES, which were combined into a scale with excellent reliability $(\alpha=.88)$. These items read: 'Today, I was inclined to feel that I am a failure' (reverse coded), 'Today, I took a positive attitude towards myself', 'Today, I was satisfied with myself' and 'Today, I thought I am no good at all' (reverse coded).

To check whether length of participation differed significantly according to the dependent and independent variables under study, we correlated the number of contributed diary report with the average of daily relationship conflict, relationship quality, SE and people's self-reported N. Participation correlated weakly negative with relationship conflicts $(r=-.15, p<.01)$ and weakly positive with relationship quality $(r=.08, p<.01)$ and SE $(r=.18, p<.01)$. These associations are significant due to the large sample size of the current study but are not particularly worrying in terms of effect size (i.e. selection bias). Importantly, individual differences in $\mathrm{N}$ were completely uncorrelated with the number of contributed diary reports $(r=.00, p=.95)$.

\section{Hierarchical linear modelling}

The intra-individual association between social inclusion and SE was modelled with the HLM 6 program (Bryk \& Raudenbush, 1992), which distinguishes between different levels of the data. On Level 1, each participant's level of daily SE was allowed to vary with daily report of social inclusion. All Level 1 analyses were run with (group mean $+\mathrm{SD}$ ) standardized predictors. An autoregressive covariance component (AR1) was added to the Level 1 model to account for the fact that daily SE is stable across days. On Level 2, the intercept (i.e. the average level of SE across days) was allowed to vary between participants. $\mathrm{N}$ was included as a predictor of both this average level (intercept) and the association between social inclusion and daily SE (slope). 


\section{Results of Study 2}

\section{Main effects}

Table 2 displays the HLM coefficients of three hierarchical models. First, a baseline model was estimated with the daily SE intercept varying randomly between participants. Second, we included relationship conflict and quality as separate predictors of daily SE fluctuations. As can be seen, both indicators exerted a significant effect on daily SE. Specifically, a strong positive association was found between daily perceptions of relationship quality and SE, whereas a somewhat smaller negative association was found between relationship conflict and SE. In the present case, the ratio between the $\beta$ parameters and the square root of their variances (i.e. their standard deviation) was 1.46 and 1.13 for relationship quality and conflict, respectively. Transformed into $z$-values, this means that $93 \%$ of all participants had positive slopes between relationship quality and SE, whereas $87 \%$ had negative slopes between relationship conflict and SE. In terms of explained variance including relationship conflict and quality as a predictor resulted in a 6.34 and $11.36 \%$ reduction in residual variance (i.e. akin to $R^{2}$; see Murray et al., 2003), respectively. Accordingly, SMT's (Leary \& Baumeister, 2000) hypothesis that SE is a function on people's perceived level of social inclusion is supported on a day-to-day level.

\section{Interaction effects}

Table 2 also shows the coefficients of the HLM models that include the interaction between social inclusion and $\mathrm{N}$ as predictors of daily SE. As can be seen, $\mathrm{N}$ interacted with daily conflict and daily relationship quality to predict daily fluctuations in SE. In the case of relationship conflict, this interaction term was negative, indicating that the negative association between conflict and SE was stronger for high-N individuals. In the case of relationship quality, the interaction was positive, indicating that the positive association between quality and SE was more positive for high-N individuals. We compared the random variance in slopes of a model with only the main effects of social inclusion and $\mathrm{N}$ and a model that also includes the corresponding interaction term. Including the interaction

Table 2. HLM regression coefficients and variances regarding the association between social inclusion and self-esteem and the moderating effect of neuroticism

\begin{tabular}{|c|c|c|c|c|c|c|c|c|c|c|}
\hline & \multicolumn{2}{|c|}{ Baseline } & \multicolumn{2}{|c|}{ Conflict } & \multicolumn{2}{|c|}{ Conflict $\times N$} & \multicolumn{2}{|c|}{ Quality } & \multicolumn{2}{|c|}{ Quality $\times N$} \\
\hline & $c$ & $\sigma^{2}$ & $c$ & $\sigma^{2}$ & $c$ & $\sigma^{2}$ & $c$ & $\sigma^{2}$ & $c$ & $\sigma^{2}$ \\
\hline Intercept & $-.08^{* *}$ & $.46^{* *}$ & $-.07^{* *}$ & $.44^{* *}$ & $-.06^{* *}$ & $.32^{* *}$ & $-.05^{* *}$ & $.36^{* *}$ & $-.04^{*}$ & $.27^{* *}$ \\
\hline AR1 $\rho$ (autoregression) & & $.22^{* *}$ & & $.22^{* *}$ & & $.22^{* *}$ & & $.22^{* *}$ & & $.22^{* *}$ \\
\hline Social inclusion & & & $-.17^{* *}$ & $.02^{* *}$ & $-.17^{* *}$ & $.02^{* *}$ & $.28^{* *}$ & $.04^{* *}$ & $.27^{* *}$ & $.04^{* *}$ \\
\hline Neuroticism & & & & & $-.34^{* *}$ & & & & $-.30^{* *}$ & \\
\hline Social inclusion $\times$ Neuroticism & & & & & $-.02^{* *}$ & & & & $.05^{* *}$ & \\
\hline AR1 diagonal (residual) & & $.57^{* *}$ & & $.53^{* *}$ & & $.53^{* *}$ & & $.50^{* *}$ & & $.50^{* *}$ \\
\hline Deviance & 5391 & 18.5 & 4908 & & 4741 & 13.1 & 4785 & 57.0 & 4626 & 64.4 \\
\hline
\end{tabular}

Note: $N=22852$ and 1601-1691 for Levels 1 and 2, respectively. $c$, HLM regression coefficient; $\sigma^{2}$, variance component. Significant variances indicate random between-person differences in the corresponding coefficient. All parameters were standardized before being inserted in the analyses. Parameters were calculated using robust standard errors.

${ }^{*} p<.05 ;{ }^{* *} p<.01$. 
between $\mathrm{N}$ and social inclusion resulted in a 1.80 and $5.46 \%$ reduction in random slope variance for relationship conflict and quality, respectively.

Finally, we checked whether the moderating influence of $\mathrm{N}$ on the association between social inclusion and daily SE was a side effect of the strong relation between $\mathrm{N}$ and SE on the trait level ( $r=-.63$ in the current study). However, controlling for the main effect of trait SE on daily SE did not substantially alter our results.

\section{Discussion of Study 2}

In Study 2, the moderating influence of $\mathrm{N}$ on the association between perceived social inclusion and SE was investigated on a day-to-day level. Consistent with SMT, results indicated that people had a higher SE on days when they perceived higher quality and less conflict-ridden relationships. Furthermore, although a positive relation between social inclusion and SE existed for a great majority of participants, it was more pronounced for highly emotionally unstable individuals. Subsequent analysis showed that this moderation effect was not a side effect of the strong association between $\mathrm{N}$ and SE on the trait level. This is consistent with the current paper's conceptualization of $\mathrm{N}$ as reflecting a predisposition to react vigilantly to threatening cues, with cues of social exclusion being a particular type of threat that has become highly salient during the course of human evolution.

\section{STUDY 3: REACTIONS TO SOCIAL AND NONSOCIAL THREATS}

In Studies 1 and 2 we presented evidence that emotionally unstable individuals react more strongly to threats to social inclusion than emotionally stable ones. Findings were consistent with our hypothesis that high-N individuals are more sensitive to cues of social exclusion. However, we have not directly compared the association between $\mathrm{N}$ and social reactivity with the association between $\mathrm{N}$ and nonsocial reactivity. According to our conceptualization of $\mathrm{N}$ as the predisposition to react vigilantly to threatening cues, $\mathrm{N}$ should be related to both kinds of sensitivity. However, as humans have acquired ecological dominance (Alexander, 1990; Flinn \& Alexander, 2007) and most Western individuals are rarely faced with life-threatening nonsocial stimuli, social threats have likely become more salient for the majority of people. Because of their greater salience, we think that social threat situations are therefore better suited to test individual differences in the threat reactivity system that are reflected in $\mathrm{N}$.

A number of studies have compared the associations between $\mathrm{N}$ and people's reactivity to social and nonsocial threats. For example Suls, Martin, \& David (1998) used a diary study to compare the effect of interpersonal conflicts on negative affect with that of non-conflict related stressors. Using a measure of negative affect that can be located in the high-arousal/unpleasant octant of the emotional circumplex (Yik, Russell, \& Barrett, 1999), they found that $\mathrm{N}$ was not only related to a higher reactivity to interpersonal conflicts, but also to non-conflict-related stressors.

Due to the low saliency of genuinely nonsocial threats in affluent Westerner societies, it is relatively difficult to collect people's reactions to such threats using the kinds of naturalistic designs we employed in Studies 1 and 2. This is because most, if not all, real-life stressors have social elements. For example work overload may be regarded as a relatively nonsocial stressor, but such problems often have social antecedents (e.g. 
problems with colleagues, lack of support) and consequences (affective spillover at home). Sure enough, it is possible to think of relatively 'pure' nonsocial stressors, such as car accidents, but these kinds of nonsocial hazards are quite infrequent. Because of this, in Study 3 we ask people to imagine how they would react to a list of stressors that was constructed to be relatively unambiguous in relating to either social or nonsocial dangers. We predicted $\mathrm{N}$ to be associated with people's reactivity to both kinds of stressors, though reactions to social (vs. non-social) stressors may be more valid indicators of $\mathrm{N}$ because of their greater saliency, ecological validity and fitness consequences in humans.

\section{Method of Study 3}

\section{Participants}

The sample of Study 3 consisted of individuals who had participated in Study 2 between July 2005 and January 2006. A total of 640 individuals received an email with a call for participation in a study into people's 'evaluations of situations'. Besides an offer to receive information regarding the scientific background of the study, no incentives for participation were offered. One week after sending the first email, a reminder was sent out to maximize participation, a second reminder was sent after another week. This resulted in a total sample size of 426 (response rate 67\%). On average, these participants completed the follow-up 9 months after they began Study 2. No differences between those who did or did not participate in this additional study were found with regards to gender or $\mathrm{N}$.

\section{Instruments and procedure}

We created a set of six threatening social and six threatening nonsocial situations for use in the current study. Regarding the socially threatening situations, participants were instructed to imagine receiving cues that social relationships with romantic partners, colleagues and friends are deteriorating (e.g. friends who do not show up at one's birthday party). Family relationships were not included as stimuli because they represent a qualitatively different type of relationship (Neyer \& Lang, 2003) and may thus fail to trigger the sociometer processes as hypothesized in the current paper. The list of nonsocial threatening situations involved threats to one's physical well-being by natural disasters, mechanical accidents and dangerous animals (see Table 3 for the translated items). The series alternated between social and nonsocial stimuli, starting with a social one. After each stimulus, participants were asked how they would feel in the corresponding situation. In an effort to increase the psychological impact of the imaginations, participants were instructed to take some time to visualize each situation.

Because changes in state SE has been hypothesized to be primarily a function of individuals' level of social inclusion (Leary \& Baumeister, 2000), we decided not to use this variable to assess people's responses to nonsocial threats. Instead, we operationalized people's sensitivity to social and nonsocial threats by means of negative affect. Participants rated the degree to which their mood in each of the 16 imagined situation could be described by four negative mood adjectives (nervous, jittery, afraid and distressed), using a 1 ('not at all') to 9 ('extremely') Likert scale. These items were chosen from the PANAS-X based on their high item-total correlations in pilot work with this instrument. The mean of these four items was taken as an index of negative reactivity to each situation, with $\alpha$ s ranging from .73 to $.89(M=0.81$, see Table 3$)$. The overall mean of participants' reactions was $5.86(\mathrm{SD}=1.73)$, indicating that our stimuli were successful in inducing negative affect. The averaged emotion ratings for the six social situations were aggregated 
Table 3. Social and nonsocial reactivity scales: item content, internal consistencies $(\alpha s)$, means and standard deviations

\begin{tabular}{|c|c|c|c|}
\hline Item & $\alpha$ & $M$ & SD \\
\hline \multicolumn{4}{|l|}{ Social threat reactivity } \\
\hline $\begin{array}{l}\text { You find out that your romantic partner has talked badly } \\
\text { about you }\end{array}$ & .78 & 6.56 & 1.56 \\
\hline $\begin{array}{l}\text { You notice that your colleagues are gossiping about you behind } \\
\text { your back }\end{array}$ & .83 & 5.93 & 1.73 \\
\hline $\begin{array}{l}\text { On the evening of your birthday party, a surprisingly low number } \\
\text { of guests showed up; many of your friends have stayed home without } \\
\text { telling you in advance }\end{array}$ & .80 & 5.72 & 1.66 \\
\hline $\begin{array}{l}\text { You notice that your romantic partner has increasingly little time } \\
\text { for joint activities with you }\end{array}$ & .86 & 5.99 & 1.79 \\
\hline $\begin{array}{l}\text { You hear that your colleagues have planned a social event without } \\
\text { inviting you }\end{array}$ & .84 & 4.69 & 1.75 \\
\hline $\begin{array}{l}\text { You notice that your friends increasingly meet with each other without } \\
\text { you }\end{array}$ & .84 & 5.83 & 1.72 \\
\hline Total scale & .86 & 5.79 & 1.31 \\
\hline \multicolumn{4}{|l|}{ Nonsocial threat reactivity } \\
\hline $\begin{array}{l}\text { You wake up at night from heavy smoke and discover that a fire has } \\
\text { broken out in the corridor }\end{array}$ & .73 & 6.75 & 1.51 \\
\hline $\begin{array}{l}\text { Driving on the highway you notice that the brakes of your car don't } \\
\text { function }\end{array}$ & .68 & 7.21 & 1.28 \\
\hline You wake up at night from a big spider crawling up your arm & .82 & 5.39 & 2.08 \\
\hline $\begin{array}{l}\text { During a long hike in nature the sky suddenly becomes dark; it looks like } \\
\text { a heavy storm is about to break loose }\end{array}$ & .87 & 4.00 & 1.94 \\
\hline $\begin{array}{l}\text { During a flight your plane suddenly looses altitude; the pilot announces } \\
\text { technical problems with the engine }\end{array}$ & .80 & 7.25 & 1.58 \\
\hline While walking home, a big, unleashed dog runs up to you & .89 & 5.02 & 2.17 \\
\hline Total scale & .75 & 5.93 & 1.20 \\
\hline
\end{tabular}

to a Social Threat Reactivity Scale $(\alpha=.86)$, the averaged ratings for the six nonsocial situations to a Nonsocial Threat Reactivity Scale $(\alpha=.76)$. Both scales were significantly correlated $(r=.59, p<.01)$, reinforcing the notion that they are rooted in a generalized predisposition to react vigilantly to threatening cues. Due to the large sample size, the means of social and nonsocial composites differed statistically from each other, $t(426)=2.66, p=01$, but the corresponding effect size was negligibly small $(d=0.12)$, so it is relatively implausible that a dissociation between social and nonsocial reactions are due to differences in the strength of people's reactions to the corresponding scales.

To avoid any negative carryover into participants' daily lives, the study ended with an instruction to imagine winning the lottery and being on vacation on a tropical island. The amount of negative emotion after imagining these closing situations was 4.34 and 1.62, respectively, suggesting that we succeeded in minimizing residual negative affect in our subjects. After finishing the study, participants were debriefed by email.

\section{Results of Study 3}

To investigate the notion that the sensitivity of the threat-monitoring system can be more accurately assessed with social (vs. nonsocial) threats (due to their greater saliency and fitness consequences), we first correlated social and nonsocial reactivity scores with 
participants' BFI N scores from Study 2. The correlation between $\mathrm{N}$ and both social and nonsocial threat reactivity was significant $(r=.29$ and $r=.21$, respectively, $p \mathrm{~s}<.01$ ). The difference between these (dependent) correlations was marginally significant, $t(404)=1.86, p=.06$. As the reliability of the social reactivity index was higher than the corresponding nonsocial one, it could be argued that the difference between these correlations is a measurement artifact. Results from additional analyses speak against this possibility: After correction for unreliability, the difference between the correlations with the social $(r=.34)$ and nonsocial $(r=.26)$ threat conditions remained marginally significant, $t(404)=1.89, p=.06$.

\section{Discussion of Study 3}

Because nonsocial threats in naturally occurring circumstances are both rare and often associated with social causes and consequences, Study 3 constructed relatively unambiguous social and nonsocial threat situations and asked participants to estimate how they would react to them. In line with our conceptionalization of $\mathrm{N}$ as reflecting individual differences in the predisposition to react vigilantly to threatening cues, we found that $\mathrm{N}$ was associated with both social and nonsocial threat reactivity. However, because social cues are likely more salient in the present participants' lives and more evolutionary relevant in humans, we also expected the association between $\mathrm{N}$ and social reactivity to be somewhat stronger than the association with nonsocial reactivity. This prediction was also confirmed.

In spite of its clear pattern of results, a number of factors limit the generalizability of Study 3's findings. First of all, the participants of Study 3 overlapped to a substantial degree with those of Study 2, so Study 3 merely replicated the social threat results from Study 2 using another method. Second, for many participants there was a relatively large time gap between the assessment of $\mathrm{N}$ and their emotional reactivity. Because of the imperfect stability of $\mathrm{N}$, this constrained the strength of the correlations found in the current study, rendering it all the more impressive that we found significant results. Third, Study 3 tracked people's reactions to imagined social and nonsocial situations. Although the use of imagination is common in mood induction studies (Westermann, Spies, Stahl, \& Hesse, 1996), results of this technique are of course limited by people's willingness and ability to imagine how they would react to various kinds of threats (Nisbett \& Wilson, 1977). Accordingly, it may be that we merely discovered that high- $\mathrm{N}$ individuals are better able to imagine socially threatening situations than low-N individuals. Of course, this represents more than just a measurement problem, as the high salience of social (vs. nonsocial) threats reflects the relatively low level of physical risk in the ecology represented by affluent Western societies. Therefore, future studies will have to rely on carefully constructed laboratory experiments to observe people's reactions to nonsocial threats.

\section{GENERAL DISCUSSION}

In the current paper, we made an attempt to test the hypothesis that $\mathrm{N}$ can be conceptualized as individual differences in people's predisposition to react vigilantly to threatening cues. Because social threats are more salient in the lives of most contemporary Westerners and likely more evolutionary relevant for our species, we tested this notion by investigating people's reactions to two indicators of social inclusion: Perceptions of relationship quality 
and conflict. According to SMT (Leary \& Baumeister, 2000), feeling socially included should be associated with increased feelings of SE. In the current paper, we predicted that this dependency is stronger for individuals high (vs. low) in N. In Studies 1 and 2, strong evidence for this position was found. Cross-sectional data showed that high-N individuals' global perceptions of social relationship quality are more strongly related to their SE than those of emotionally stable people. In a similar vein, results from a diary study showed that the daily SE of high-N people is more dependent on perceptions of relationship quality and conflict. Finally, results from an imagination study suggest that $\mathrm{N}$ is associated with a heightened sensitivity to both social and nonsocial threats, even though the former association was somewhat stronger.

Our finding that $\mathrm{N}$ is associated with a greater sensitivity to cues of social inclusion is consistent with recent empirical and theoretical correlates found for SE, attachment, depression and gender, suggesting possible theoretical links between these variables. Regarding SE, it has been reported that the sociometer of low-SE individuals is more sensitive to cues of social inclusion (Murray et al., 2003), which is consistent with the finding that $\mathrm{N}$ and SE are very closely related (Judge et al., 2002). As stated earlier, both constructs are likely reciprocally related as well as connected to third factors such as past experiences of rejection and negative response tendencies.

Insecurely attached individuals' sociometers have also been reported to be more sensitive to signs of social inclusion than those of securely attached individuals (Srivastava \& Beer, 2005). While attachment theorists like to view individual differences in attachment security as the developmental outcome of the universal human attachment system in interaction with varying interpersonal experiences (e.g. Fraley \& Shaver, 2000), it may be that (heritable) aspects of N may moderate people's sensitivity to these experiences.

Evolutionary theorists have also postulated the sensitivity to signs of social exclusion as one of the central features of depressed mood (Allen \& Badcock, 2003). As N is strongly associated with depression (e.g. Fanous, Gardner, Prescott, Cancro, \& Kendler, 2002; Schmitz, Kugler, \& Rollnik, 2003), it may be that the vigilant strategy of individuals with a depressed mood to deal with threats to social inclusion is dispositionally shared by people with stable high levels of $\mathrm{N}$.

Finally, the current results may allow some speculations regarding the origin of gender differences in N and SE (for meta-analyses, see Feingold, 1994; Kling, Hyde, Showers, \& Buswell, 1999). According to the current perspective, such differences may indicate that women are more sensitive to threats, which in today's environment (at least in relatively affluent countries) are often of a social nature. In part, this may reflect differences in relationship goals (Maccoby, 1990): whereas women are more focused on positive reciprocity (getting along), men are more focused on negative reciprocity (getting ahead). Ultimately, these gender differences might reflect sex differences in minimal parental investment, which make women more dependent on social support from close others. However, more research is necessary to substantiate this speculation.

As stated earlier, some researchers have conceptualized $\mathrm{N}$ as mental noise or general negative affectivity, painting a highly maladaptive picture of this trait. From a Darwinian perspective, such an account appears unlikely, since natural selection should have eliminated such obvious maladaptive tendencies during the course of evolution. An alternative possibility is that both extremes of the $\mathrm{N}$ continuum are maladaptive, leading to a selection pressure towards intermediate levels. That argument would regard normal range between-person variation in this trait as random noise (an argument called selective 
neutrality; Tooby \& Cosmides, 1990). However, the degree of neutrality that is required for such a scenario is quite implausible for a major personality dimension like $\mathrm{N}$.

As stated previously, we think it's more likely that the adaptive consequences of $\mathrm{N}$ depend on the kind of environment an individual is confronted with (Penke et al., 2007a,b). For example in harsh environments that make biparental care necessary for the survival of offspring, preserving social ties seems much more important than in affluent environments. Because Western individuals are currently living in a relatively affluent, risk-free environment, the stress and vigilance that is associated with $\mathrm{N}$ may seem entirely maladaptive, but anthropological records provide good reasons to believe that we frequently encountered environmental conditions during our evolutionary history where social ties were crucial (e.g. Harpending \& Cochran, 2002), which makes adaptive benefits of high $\mathrm{N}$ more likely. Note also that it is not subjective well-being or relationship satisfaction what counts from an evolutionary perspective, but the degree to which social support is actually received.

As a final consideration, it should be noted that the effect sizes that were found in the current studies were relatively small. Accordingly, it can be asked whether differences in the sensitivity to (social) threats are really a central feature of $\mathrm{N}$-or only an epiphenomenon. For example the effect sizes of the interaction between $\mathrm{N}$ and social inclusion reported in Studies 1 and 2 were not dramatic. It should be noted, however, that the need to belong has been called a universal human motive (Baumeister \& Leary, 1995), so that personality can only affect the degree to which people react negatively to signs of social exclusion. More generally, it is necessary to keep in mind that small effects can have cumulative consequences. For example it has been shown that people who are sensitive to social rejection perceive ambiguous cues as threats to social inclusion and overreact to them, reducing both partners' relationship satisfaction (Downey \& Feldman, 1996) and increasing the frequency of relationship conflicts, leading to decreases in SE, and so forth. Indeed, such reciprocal cycles may lead to a deepening and cementation of initially existing individual differences in N (i.e. cumulative continuity; Caspi, Roberts, \& Shiner, 2005).

\section{Limitations and strengths}

A number of different assets of the current investigation stand out as strengths. First of all, the current results were consistent across different methods (ego-centred social network instrument, online diary, imagined social and nonsocial threats), reducing the likelihood that they are caused by method artifacts. Also, results were consistent across two different instruments to assess N: the NEO-FFI and the BFI and were based on relatively large samples, especially the diary study. Of course, the current investigation also suffers from several limitations. Importantly, the current results were invariantly based on self-reports of naturally occurring behaviour. Although this represents a strength with regards to ecological validity, it also means that participants may have selected themselves into certain niches that are consistent with their personalities, possibly affecting the processes that were investigated. It is therefore possible that stronger conclusions could be reached by observing individuals' reactions to experimentally manipulated cues to social inclusion. Another important limitation was the relatively biased sample of Studies 2 and 3. The majority of participants were women, which restricts the generalizability of the current findings to men and highlights a need for research with more representative samples. A final limitation is the correlational nature of our studies, which limits our ability to draw 
conclusions about causality. For example it could also be that SE is more likely to impact the quality of social relationships among individuals who are high (vs. low) in N. Such alternatives should be tested in future experiments.

\section{CONCLUSION}

We found considerable support for a motivational predisposition to react vigilantly to threatening cues as a central feature of $\mathrm{N}$ (for potential others, see Nettle, 2006). By framing the processes behind $\mathrm{N}$ in neutral instead of psychopathological terms, it becomes possible to see this trait from a functionalistic perspective, with its evolutionary fitness payoffs being dependent on the specific (social) environment of the individual. This conceptualization thus offers balancing selection as an answer to the nontrivial question how the genetic variance that partly underlies $\mathrm{N}$ is maintained in the population (Penke et al., 2007a,b). Most alternative conceptualizations generally fail to provide an answer here. Furthermore, by specifying the kinds of situations in which the trait of $\mathrm{N}$ is most relevant, as well as the outcomes behaviours associated with it, the current conceptualization may serve as a bridge to reconcile process-oriented approaches (e.g. sociometer theory) with trait approaches to the study of personality (Revelle, 1995). We thus believe that the current results can contribute to the emergence of a more theoretically based trait paradigm in personality psychology and hope that future studies continue this line of inquiry.

\section{REFERENCES}

Alexander, R. D. (1990). How did humans evolve? Reflections on the uniquely unique species. Museum of Zoology (Special Publication No. 1). Ann Arbor: The University of Michigan.

Allen, N. B., \& Badcock, P. B. T. (2003). The social risk hypothesis of depressed mood: Evolutionary, psychosocial, and neurobiological perspectives. Psychological Bulletin, 129, 887-913.

Asendorpf, J. B., \& Wilpers, S. (1998). Personality effects on social relationships. Journal of Personality and Social Psychology, 74, 1531-1544.

Barrett, L. F., \& Pietromonaco, P. R. (1997). Accuracy of the five-factor model in predicting perceptions of daily social interactions. Personality and Social Psychology Bulletin, 23, $1173-1187$.

Baumeister, R. F., \& Leary, M. R. (1995). The need to belong: Desire for interpersonal attachments as a fundamental human motivation. Psychological Bulletin, 117, 497-529.

Bolger, N., \& Schilling, E. A. (1991). Personality and the problems of everyday life: The role of neuroticism in exposure and reactivity to daily stressors. Journal of Personality, 59, 355-386.

Bolger, N., \& Zuckerman, A. (1995). A framework for studying personality in the stress process. Journal of Personality and Social Psychology, 69, 890-902.

Borkenau, P., \& Ostendorf, F. (1993). NEO-Fünf-Faktoren Inventar (NEO-FFI) (NEO-five-factor inventory). Göttingen: Verlag für Psychologie.

Bryk, A. S., \& Raudenbush, S. W. (1992). Hierarchical linear models in social and behavioral research: Applications and data analysis methods. Newbury Park: Sage Publications.

Bushman, B. J., \& Baumeister, R. F. (1998). Threatened egotism, narcissism, self-esteem, and direct and displaced aggression: Does self-love or self-hate lead to violence? Journal of Personality and Social Psychology, 75, 219-229.

Carver, C. S., Sutton, S. K., \& Scheier, M. F. (2000). Action, emotion, and personality: Emerging conceptual integration. Personality and Social Psychology Bulletin, 26, 741-751.

Caspi, A., Roberts, B. W., \& Shiner, R. L. (2005). Personality development: Stability and change. Annual Review of Psychology, 56, 453-484. 
Church, A. T. (1994). Relating the Tellegen and five-factor models of personality structure. Journal of Personality and Social Psychology, 67, 898-909.

Costa, P. T., \& McCrae R. R. (1992). Revised NEO personality inventory (NEO PI-R) and NEO five-factor inventory (NEO-FFI): Professional manual. Odessa: Psychological Assessment Resources.

Downey, G., \& Feldman, S. I. (1996). Implications of rejection sensitivity for intimate relationships. Journal of Personality and Social Psychology, 70, 1327-1343.

Elliot, A., \& Thrash, T. (2002). Approach-avoidance motivation in personality: Approach and avoidance temperaments and goals. Journal of Personality and Social Psychology, 82, 804-818.

Eysenck, H. J. (1944). Types of personality: A factorial study of 700 neurotics. Journal of Mental Science, 90, 851-861.

Eysenck, H. J. (1990). Biological dimensions of personality. In L. A. Pervin (Ed.), Handbook of personality: Theory and research (pp. 244-276). New York: Guilford.

Fanous, A., Gardner, C. O., Prescott, C. A., Cancro, R., \& Kendler, K. S. (2002). Neuroticism, major depression and gender: a population-based twin study. Psychological Medicine, 32, 719-728.

Feingold, A. (1994). Gender differences in personality: A meta-analysis. Psychological Bulletin, 116, 429-456.

Fleeson, W. (2001). Toward a structure- and process-integrated view of personality: Traits as density distributions of states. Journal of Personality and Social Psychology, 80, 1011-1027.

Flinn, M. V., \& Alexander, R. D. (2007). Runaway social selection in human evolution. In S. W. Gangestad, \& J. A. Simpson (Eds.), The evolution of mind: Fundamental questions and controversies (pp. 249-255). New York: Guilford.

Fraley, R., \& Shaver, P. R. (2000). Adult romantic attachment: Theoretical developments, emerging controversies, and unanswered questions. Review of General Psychology, 4, 132-154.

Gangestad, S. W., \& Simpson, J. A. (2000). The evolution of human mating: Trade-offs and strategic pluralism. Behavioral and Brain Sciences, 23, 573-644.

Gross, J. J., Sutton, S. K., \& Ketelaar, T. (1998). Relations between affect and personality: Support for the affect level and affective reactivity views. Personality and Social Psychology Bulletin, 24, 279-288.

Gunthert, K. C., Cohen, L. H., \& Armeli, S. (1999). The role of neuroticism in daily stress and coping. Journal of Personality and Social Psychology, 77, 1087-1100.

Harpending, H., \& Cochran, G. (2002). In our genes. Proceedings of the National Academy of Sciences of the United States of America, 99, 10-12.

Heatherton, T. F., \& Vohs, K. D. (2000). Interpersonal evaluations following threats to self: Role of self-esteem. Journal of Personality and Social Psychology, 78, 725-736.

John, O. P., \& Srivastava, S. (1999). The big five trait taxonomy: History, measurement and theoretical perspectives. In L. A. Pervin, \& O. P. John (Eds.), Handbook of personality: Theory and Research (pp. 102-138). New York: Guilford Press.

Judge, T. A., Erez, A., Bono, J. E., \& Thoresen, C. J. (2002). Are measures of self-esteem, neuroticism, locus of control, and generalized self-efficacy indicators of a common core construct? Journal of Personality and Social Psychology, 83, 693-710.

Kling, K. C., Hyde, J. S., Showers, C. J., \& Buswell, B. N. (1999). Gender differences in self-esteem: A meta-analysis. Psychological Bulletin, 125, 470-500.

Körner, A., Geyer, M., \& Brähler, E. (2002). Das NEO-Fünf-Faktoren Inventar (NEO-FFI): Validierung anhand einer deutschen Bevölkerungsstichprobe. Diagnostica, 48, 19-27.

Larsen, R. J., \& Ketelaar, T. (1989). Extraversion, neuroticism, and susceptibility to positive and negative mood induction procedures. Personality and Individual Differences, 10, 1221-1228.

Leary, M. R., \& Baumeister, R. F. (2000). The nature and function of self-esteem: Sociometer theory. In M. P. Zanna (Ed.), Advances in experimental social psychology (Vol. 32, pp. 1-62). San Diego: Academic Press.

Leary, M. R., Tambor, E. S., Terdal, S. K., \& Downs, D. L. (1995). Self-esteem as an interpersonal monitor: The sociometer hypothesis. Journal of Personality and Social Psychology, 68, 518530.

Maccoby, E. E. (1990). Gender and relationships: A developmental account. American Psychologist, 45, 513-520.

Marsh, H. W. (1992). Self Description Questionnaire (SDQ) III: A theoretical and empirical basis for the measurement of multiple dimensions of late adolescent self-concept: An interim 
test manual and a research monograph. Macathur: University of Western Sydney, Faculty of Education.

Matthews, G. (2004). Neuroticism from the top down: Psychophysiology and negative emotionality. In R. M. Stelmack (Ed.), On the psychobiology of personality: Essays in honor of Marvin Zuckerman (pp. 249-266). New York: Elsevier Science.

Mroczek, D. K., \& Almeida, D. M. (2004). The effect of daily stress, personality, and age on daily negative affect. Journal of Personality, 72, 355-378.

Murray, S. L., Griffin, D. W., Rose, P., \& Bellavia, G. M. (2003). Calibrating the sociometer: The relational contingencies of self-esteem. Journal of Personality and Social Psychology, 85, 63-84.

Nettle, D. (2006). The evolution of personality variation in humans and other animals. American Psychologist, 61, 622-631.

Neyer, F. J. (1997). Free recall or recognition in collecting egocentered networks: The role of survey techniques. Journal of Social and Personal Relationships, 14, 305-316.

Neyer, F. J., \& Lang, F. R. (2003). Blood is thicker than water: Kinship orientation across adulthood. Journal of Personality and Social Psychology, 84, 310-321.

Neyer, F. J., \& Lehnart, J. (2007). Relationships matter in personality development: Evidence from an 8-year longitudinal study across young adulthood. Journal of Personality, 75, 535-568.

Nezlek, J. B., \& Plesko, R. M. (2003). Affect- and self-based models of relationships between daily events and daily well-being. Personality and Social Psychology Bulletin, 29, 584-596.

Nezlek, J. B., \& Wheeler, L. (1984). RIRAP: Rochester interaction record analysis package. Psychological Documents, 14, 6. (Ms. No. 2610.)

Nisbett, R., \& Wilson, T. (1977). Telling more than we can know: Verbal reports on mental processes. Psychological Review, 84, 231-259.

Norris, C. J., Larsen, J. T., \& Cacioppo, J. T. (2007). Neuroticism is associated with larger and more prolonged electrodermal responses to emotionally evocative pictures. Psychophysiology, 44, 823-826.

Ozer, D. J., \& Benet-Martínez, V. (2006). Personality and the prediction of consequential outcomes. Annual Review of Psychology, 57, 401-421.

Penke, L., Denissen, J. J. A., \& Miller, G. F. (2007a). The evolutionary genetics of personality. European Journal of Personality, 21, 549-587.

Penke, L., Denissen, J. J. A., \& Miller, G. F. (2007b). Evolution, genes, and inter-disciplinary personality research. European Journal of Personality, 21, 639-665.

Raevuori, A., Dick, D., Keski-Rahkonen, A., Pulkkinen, L., Rose, R., Rissanen, A., et al. (2007). Genetic and environmental factors affecting self-esteem from age 14 to 17: A longitudinal study of Finnish twins. Psychological Medicine, 37, 1625-1633.

Revelle, W. (1995). Personality processes. Annual Review of Psychology, 46, 295-328.

Robinson, M. D., \& Tamir, M. (2005). Neuroticism as mental noise: A relation between neuroticism and reaction time standard deviations. Journal of Personality and Social Psychology, 89, 107 114.

Rosenberg, M. (1965). Society and the adolescent self-image. Princeton: Princeton University Press.

Schmitz, N., Kugler, J., \& Rollnik, J. (2003). On the relation between neuroticism, self-esteem and depression: Results from the National Comorbidity Survey. Comprehensive Psychiatry, 42, $166-173$.

Schwanzer, A. (2002). Entwicklung und Validierung eines deutschsprachigen Instruments zur Erfassung des Selbstkonzepts junger Erwachsener (Materialien aus der Bildungsforschung, $\mathrm{Nr}$. 74). Berlin: Max-Planck-Institut für Bildungsforschung.

Srivastava, S., \& Beer, J. S. (2005). How self-evaluations relate to being liked by others: Integrating sociometer and attachment perspectives. Journal of Personality and Social Psychology, 89, 966-977.

Suls, J., Green, P., \& Hillis, S. (1998). Emotional reactivity to everyday problems, affective inertia, and neuroticism. Personality and Social Psychology Bulletin, 24, 88-98.

Suls, J., Martin, R., \& David, J. P. (1998). Person-environment fit and its limits: Agreeableness, neuroticism, and emotional reactivity to interpersonal conflict. Personality and Social Psychology Bulletin, 24, 88-98.

Tellegen, A. (1985). Structures of mood and personality and their relevance to assessing anxiety, with an emphasis on self-report. In A. H. Tuma, \& J. D. Maser (Eds.), Anxiety and the anxiety disorders (pp. 681-706). Hillsdale: Lawrence-Erlbaum. 
Tooby, J., \& Cosmides, L. (1990). On the universality of human nature and the uniqueness of the individual: The role of genetics and adaptation. Journal of Personality, 58, 17-67.

Twenge, J. M. (2000). The age of anxiety? The birth cohort change in anxiety and neuroticism, 1952-1993. Journal of Personality and Social Psychology, 79, 1007-1021.

Watson, D., \& Casillas, A. (2003). Neuroticism: Adaptive and maladaptive features. In E. C. Chang, \& L. J. Sanna (Eds.), Virtue, vice, and personality: The complexity of behavior (pp. 145-161). Washington, DC: American Psychological Association.

Westermann, R., Spies, K., Stahl, G., \& Hesse, F. W. (1996). Relative effectiveness and validity of mood induction procedures: A meta-analysis. European Journal of Social Psychology, 26, $557-580$.

Yik, M. S. M., Russell, J. A., \& Barrett, L. F. (1999). Structure of self-reported current affect: Integration and beyond. Journal of Personality and Social Psychology, 77, 600-619.

Zautra, A. J., Affleck, G. G., Tennen, H., Reich, J. W., \& Davis, M. C. (2005). Dynamic approaches to emotions and stress in everyday life: Bolger and Zuckerman reloaded with positive as well as negative affects. Journal of Personality, 73, 1511-1538.

Zuckerman, M., Joireman, J. A., Kraft, M., \& Kuhlman, M. (1999). Where do motivational and emotional traits fit within three factor models of personality? Personality and Individual Differences, 26, 487-504. 